\title{
REDD+ policy networks in Vietnam
}

\author{
Pham Thu Thuy, Moira Moeliono and Le Ngoc Dung
}

\section{Key messages}

- Reducing Emissions from Deforestation and forest Degradation and Enhancing Forest Carbon Stocks (REDD+) in Vietnam is one of the few policy processes where actors including the State, international nongovernmental organizations (INGOs) and civil society organizations (CSOs) are vocal about taking part in the policy arena.

- A policy network analysis, however, shows that governance of REDD+ remains centralized within a few government agencies (e.g. Ministry of Agriculture and Rural Development) and donors (e.g. UN-REDD) as indicated by their level of influence, frequency of information-sharing with other actors and level of collaboration with other actors.

- Stakeholders identified corruption; ineffective consultation processes leading to lack of inclusion in decision making; limited role of scientists in decision making; and lack of coordination among government agencies and donors as major governance challenges for REDD+ in Vietnam.

- The issue of strongest disagreement and polarization in the policy arena is about REDD funding and how it should be disbursed - whether REDD+ should be merged with existing state budget lines or set up as an independent fund outside these structures.

\section{Introduction}

While Vietnam is one of the few tropical countries that has recently increased its forest cover, the quality of forests has decreased over time (Hoang et al. 2010). It is also one of five countries expected to be most affected by climate change, due to its long coastline, high concentration of people and high pressure on natural resources for economic development (UNFCCC 2007). The country was selected in 2009 as a pilot for REDD+ under a program funded by the Government of Norway, and it participates in the World Bank-administered Forest Carbon Partnership Facility (FCPF).

\section{The proclamation of Decision No.799/QD-TTg by the Prime Minister that establishes the National Action Plan for REDD+ shows Vietnam's strong commitment to REDD+. In this plan, the government aims to reduce greenhouse gas (GHG) emissions from the agricultural sector by $20 \%$ and increase forest cover to $45 \%$ by 2020 .}

From the beginning, the REDD+ process in Vietnam has engaged a wide range of stakeholders - from government actors and international organizations to nongovernmental organizations (NGOs), civil society organizations (CSOs) and the private sector. Until now, however, there has been limited understanding of who has been making national REDD+ policy and why, as well as about perceptions of the key stakeholders particularly with regard to implementation.

To address these knowledge gaps, the Center for International Forestry Research (CIFOR) conducted a study to identify the actors involved in national REDD+ policy making; their perceptions, interests and power relations; their networks of information exchange; and their relationship to each other (Brockhaus and Di Gregorio 2012; Pham et al. 2014). In this policy brief, we reveal the most influential actors, and how they exchange information and collaborate. Data were collected between 2011/2012 through a structured questionnaire and semi-structured interviews.

\section{REDD+ decision making in Vietnam is a multistakeholder process, but government agencies and donors are the most influential actors}

We identified 52 core organizations involved in national REDD+ policy making. We classified policy actors into five categories: government agencies (15), business sector (8), national NGOs and CSOs (4), international NGOs and donors (20), and media (5).

Policy network analysis was conducted, using questionnaires and interviews to gather information about the relationships within defined groups, who they thought was most influential, with whom they regularly exchanged information and with whom they regularly collaborated on matters of REDD+ policy making. Responses were analyzed through a social network analysis approach (Wasserman and Faust 1994), as well as qualitative analysis.

Social network analysis shows the pattern of social relationships among actors. Each respondent organization is represented as a node and its relationship (information exchange, collaboration) is presented by connected ties. In this brief, "degree" refers to an organization's number of ties, a measure of an organization's prominence that is robust to omitted data (Borgatti and Foster 2003). "Indegree" is the number of ties directed toward a node 
No. 78

(in our network, for example, the number of organizations that reported collaboration with the organization in question), and "outdegree" is the number directed away from a node (the number of organizations that a given organization reports as collaborators). Among actors involved in formulating REDD+ policy, stakeholders perceived government agencies and donors, in particular the Ministry of Agriculture and Rural Development (MARD - node number 009) and the UN-REDD (node number 018) program as the most influential agents (see Figures $1,2,3$ ).

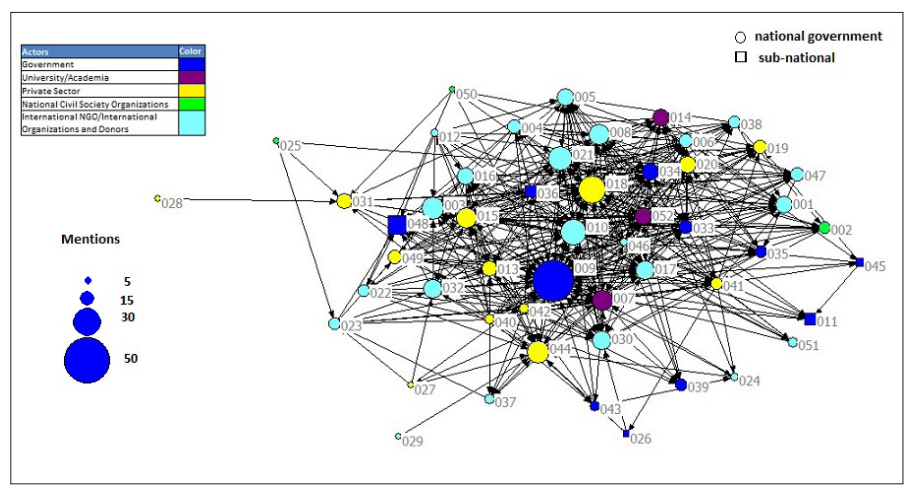

Figure 1. Network of influence.

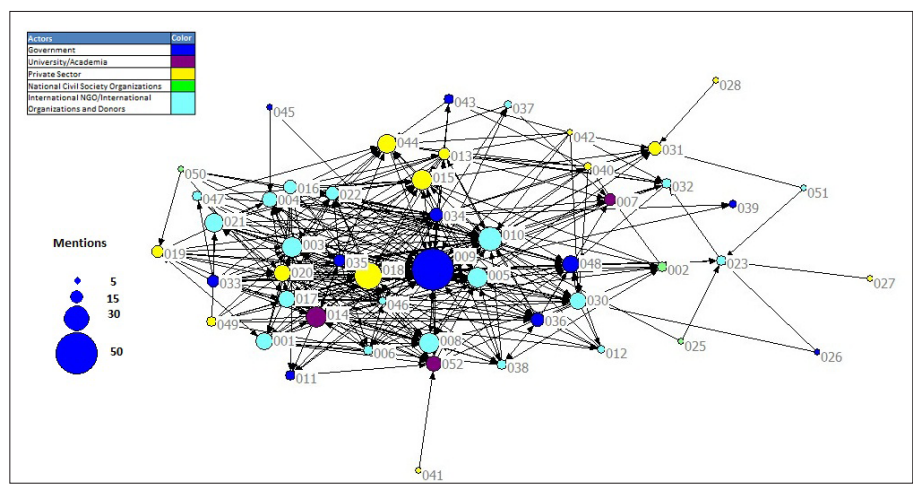

Figure 2. Information network.

Note: Organizations more frequently nominated as information exchange partners are represented by larger nodes. Node type by color

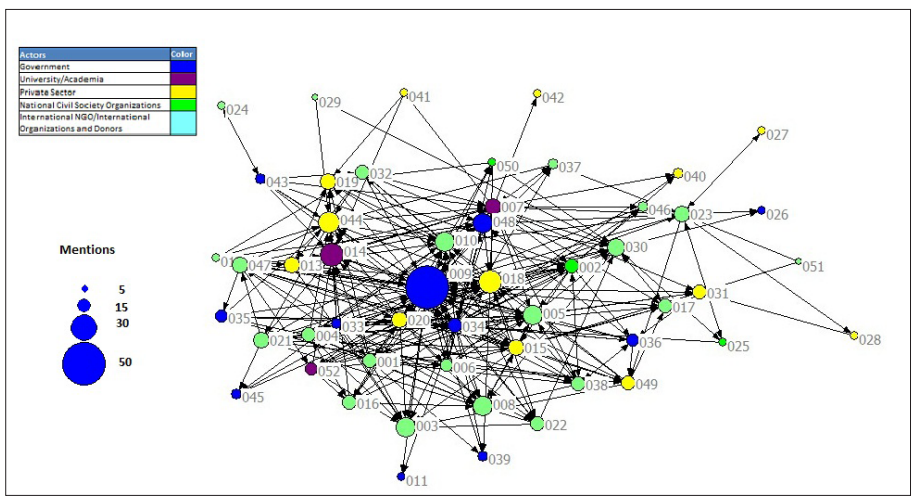

Figure 3. Collaboration network.

Note: Organizations that nominated more information exchange partners represented by larger nodes. Node type by color
"Influence" is understood as the actors' influence on REDD+ policy making based on institutional importance and contribution of their activities to REDD (such as providing sustainable funding to other organizations and offering technical or strategic information). Stakeholders saw MARD as the most influential actor because it is the national agency responsible for agriculture, forestry, fisheries, irrigation, salt production and rural development. This ministry is also the focal point for developing the REDD+ strategy and coordinating activities by leading the national REDD+ steering committee, REDD+ network and REDD+ sub-technical working group. Furthermore, with a budget estimated at USD 30 million for phase II, Vietnam is one of the first countries to carry out the United Nations Collaborative Programme on Reducing Emissions from Deforestation and forest Degradation in Developing Countries (UN-REDD program); thus, the program was also perceived as an influential actor. Conversely, stakeholders viewed CSOs and the private sector as marginalized actors with limited influence over the REDD+ policy arena.

Figures 2 and 3 show that despite the emphasis on multistakeholder consultation in REDD+, only a few actors (e.g. MARD and UN-REDD) are perceived as playing a dominant role in information exchange and as working in collaboration. In general, stakeholders have routine discussions with MARD (009) and UN-REDD (018) on REDD+ issues. Other stakeholders share and update REDD information with international NGOs/donors more than they do with government agencies playing the same role. Actors considered to be influential are also those with whom stakeholders often want to collaborate. MARD (009), UN-REDD (018) and the Japan International Cooperation Agency (JICA) (014) are influential actors (Figure 3) who also have the most collaboration with other stakeholders.

\section{Major governance challenges for REDD+ implementation in Vietnam: Stakeholders' perspectives}

All stakeholders interviewed highlighted that Decree 99 and the national REDD+ program have provided a solid legal platform and institutional setting for future REDD+ implementation. All interviewees from all actors' groups, however, shared common views on four major challenges for REDD+ implementation:

- Ineffective consultation and knowledge-sharing during the strategy development, leading to lack of support from non-state actors and local government agencies for REDD+ implementation. As government agencies and donors dominate current discussions, CSO and NGO interviewees did not feel their contributions were taken into account in final decisions.

- $\quad$ A limited role for scientists and scientific evidence to help implement and adapt REDD+ policy on the ground. While government agencies and donors acknowledged the need for evidence-based decision making, they were also sceptical about the timely arrival of such knowledge, the limited capacity of technical staff and the existence of adequate human resources.

- Transparency and accountability. Most stakeholders, particularly donors, NGOs and CSOs, expressed strong reservations about government agencies controlling all REDD+ accounting and payments. 
- Weak coordination/collaboration and limited information exchange among government agencies. Half of the interviewees highlighted weak information-sharing and collaboration among government agencies, particularly MARD and the Ministry of Natural Resources and Environment (MONRE). While MARD is responsible for forest protection and management, MONRE is in charge of land-use planning and of reporting to UNFCCC on national emission levels. While these two organizations are clearly linked, limited attempts have been made to enhance their collaboration in REDD activities, including working together on the national framework document for monitoring, reporting and verification (MRV), the development of which is supported by the Food and Agriculture Organization (FAO). All INGOs and donors interviewed noted that the limited involvement of the Ministry of Planning and Investment and Ministry of Finance also make REDD-related problems more difficult to solve.

\section{Stakeholders' biggest disagreement: How REDD funding should be disbursed}

According to Pham et al. (2012), the current proposal under the national REDD+ program seeks to create a national REDD+ trust fund. Figure 4 shows the different opinions of 52 organizations to the idea that REDD+ schemes should only be financed through a trust fund. This statement separated interviewees into three groups: those that agree (36\%), those that disagree (25\%) and those that are not sure (39\%).

Due to their rich experience in managing similar funds (e.g. programs 327 and 661 — the largest national reforestation programs) and their reluctance to use other approaches without actual experience, $30 \%$ of government agencies advocated using a trust fund to channel REDD+ funding. However, all national NGOs and CSOs pointed out that the government-managed Forest Protection and Development Fund (FPDF) — that runs a payment for ecosystem services (PES) scheme - has struggled to collect payment from buyers and distribute revenues to providers. On the one hand, many buyers have refused or delayed payment to the FPDF; also because of its limited staff, the FPDF has not been able to collect PES payments on time. On the other hand, because many sellers are located in remote areas, the FPDF often cannot pay on time or regularly. In addition, lack of transparency and accountability in other program funds have made these stakeholders dubious of using only a trust fund for REDD+ funding. Furthermore, most international organizations and donors interviewed, which have experience with elite capture and corruption in government projects, still questioned the idea of using only the trust fund.

There were also different views on whether all REDD+ accounting and payment should go through national governments (Figure 5). As shown in Figure 5, responses to the question of whether all REDD+ accounting and payments going through national governments appear polarized. While government agencies and the private sector agreed, national NGOs, donors, media and notably $60 \%$ of international organizations disagreed, due to concerns about corruption and misuse as indicated earlier.

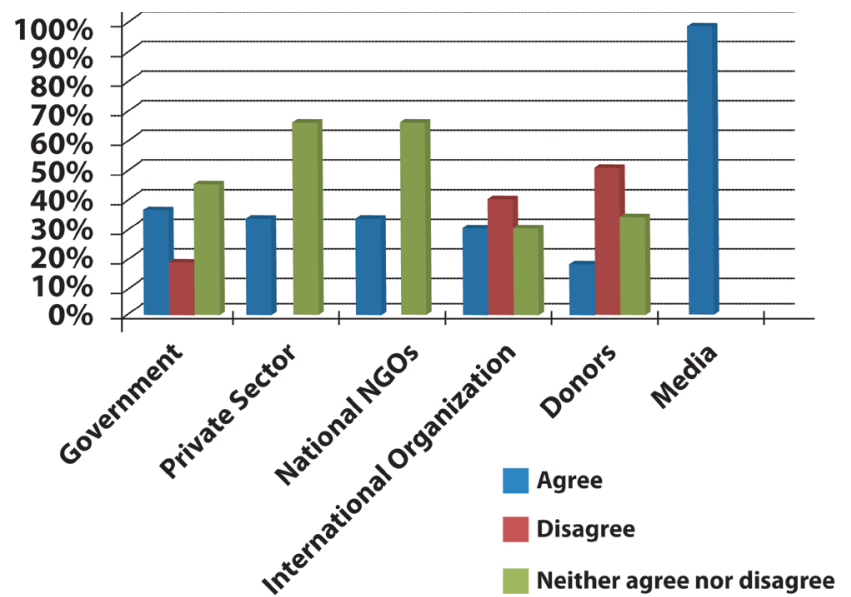

Figure 4. REDD schemes should only be financed through a trust fund.

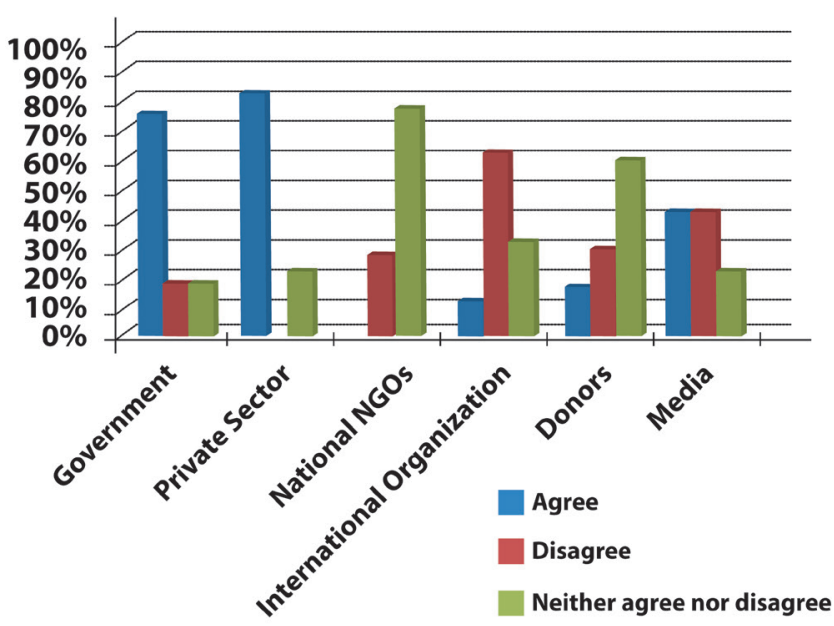

Figure 5. All REDD+ accounting and payments should go through national governments.

\section{Conclusion}

Vietnam has demonstrated its commitment to develop national REDD+ policies and a process to involve various stakeholders. A few actors dominate this process, however. This lack of inclusiveness points to the need for better coordination and information exchange among government agencies to implement REDD+ effectively. What pathway Vietnam should follow also depends on whether it can achieve this coordination and reach consensus on the political vision and interests of powerful groups on, for example, the contested funding mechanism shown in this brief. 


\section{Acknowledgements}

This research is part of the policy component of CIFOR's global comparative study (GCS) http://www.forestsclimatechange.org/ global-comparative-study-on-redd.html, led by Maria Brockhaus. Our methods build on work in COMPON (Comparing Climate Change Policy Networks, http://compon.org/), led by Jeffrey Broadbent and financially supported by the National Science Foundation (NSF). Monica Di Gregorio and Maria Brockhaus adapted the COMPON research "Protocol for Policy Network Analysis."

The authors would like to express their special thanks to all the people and organizations who agreed to take part in our interviews. Without their kind support and enthusiasm, our work would not have been conducted. Special thanks to Louis Verchot, Monica Di Gregorio, Maria Brockhaus, Riccardo De Vita, Efrian Muharrom, Christine Wairata and Ria Widjaja-Adhi for their input, support and valuable comments for our report. We gratefully acknowledge support from the Norwegian Agency for Development Cooperation, the Australian Agency for International Development, the European Commission and the UK Department for International Development.

\section{References}

Borgatti, SP and Foster, PC. 2003. The network paradigm in organizational research: A review and typology. Journal of Management 29(6):991-1013

Brockhaus M and Di Gregorio M. 2012. A brief overview: Component 1 on national REDD+ policies and processes. InfoBrief No. 13. Bogor, Indonesia: CIFOR. http://www.cifor.org/publications/ pdf_files/infobrief/3858-infobrief.pdf

Hoang MH, Pham TT, Do TH and Thomas D. 2010 An assessment of options for reducing emissions from all land uses in Vietnam - ready for REDD. World Agroforestry Centre (ICRAF), Hanoi, Vietnam.

Pham T, Di Gregorio M, Carmenta R, Brockhaus M and Le D. 2014. The REDD+ policy arena in Vietnam: Participation of policy actors. Ecology and Society 19(2):22

Pham TT, Moeliono M, Nguyen TH, Nguyen HT and Vu TH. 2012. The context of REDD+ in Vietnam: Drivers, agents and institutions. Occasional Paper No. 75. Bogor, Indonesia: CIFOR.

Pham, T. 2011. REDD+ politics in the media: A case study from Vietnam. Working Paper No. 53. Bogor, Indonesia: CIFOR.

Wasserman, K and Faust, K. 1994. Social Network Analysis. Methods and Applications. Cambridge University Press.

\begin{tabular}{|c|c|c|}
\hline$\underbrace{\text { bj }}_{\text {CGIAR }}$ & $\begin{array}{l}\text { RESEARCH } \\
\text { PROGRAM ON } \\
\text { Forests, Trees and } \\
\text { Agroforestry }\end{array}$ & $\begin{array}{l}\text { This research was carried out by CIFOR as part of the CGIAR Research Program on Forests, Trees and } \\
\text { Agroforestry (CRP-FTA). This collaborative program aims to enhance the management and use of } \\
\text { forests, agroforestry and tree genetic resources across the landscape from forests to farms. CIFOR } \\
\text { leads CRP-FTA in partnership with Bioversity International, CATIE, CIRAD, the International Center for } \\
\text { Tropical Agriculture and the World Agroforestry Centre. }\end{array}$ \\
\hline
\end{tabular}

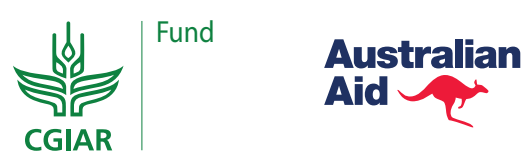

cifor.org 